\title{
Understanding Epistemological Development in First- and Second-Year Chemistry Students
}

\author{
Kristina M. Mazzarone and Nathaniel P. Grove* \\ Department of Chemistry and Biochemistry, University of North Carolina Wilmington, Wilmington, North Carolina 28403, \\ United States
}

ABSTRACT: Epistemological beliefs-a learner's perspective about knowledge and the nature of learning-have been found to play a vital role in learning. Much research has been conducted, both in general and in specific fields, to explore epistemological development in college-aged students; however, little of that research has been done specifically in chemistry. Prior research has documented how chemistry-specific epistemological beliefs change as students progress through their study of chemistry. The current research, which uses a qualitative, longitudinal approach, expands upon this work and explores factors, both curricular and extracurricular, that influence the development of students' epistemological beliefs about learning chemistry. This manuscript specifically focuses on development during students' study of chemistry during their first and second years.

KEYWORDS: First-Year Undergraduate/General, Second-Year Undergraduate, Chemical Education Research

FEATURE: Chemical Education Research

\section{INTRODUCTION}

Although researchers have been studying epistemological beliefs and their development in secondary- and tertiary-level students for nearly 50 years, some questions remain as to what those beliefs actually encompass. ${ }^{1}$ In the most basic sense, epistemological beliefs comprise a dynamic set of ideas about the nature of knowing and knowledge. The literature is replete with models describing epistemological development; however, most of these models can ultimately trace their roots to the work of William Perry, ${ }^{2}$ a researcher who studied intellectual and ethical development in students from Harvard and Radcliffe during the 1960s. According to the Perry scheme, college-aged students can be categorized into one of four broad stages: dualism; multiplism; relativism; and commitment in relativism. ${ }^{2}$

Dualistic students view the world in terms of absolutes: something is either right or wrong; it is black or white, good or evil. From such a perspective, the Authority-be it God, a parent, or the professor-is the ultimate source of knowledge, leaving little room for shades of gray. As students begin to mature epistemologically, a recognition develops that the world around them is much more complex than originally thought, and as such, the dualistic belief in a dichotomy begins to be replaced with that of a continuum. So-called multiplistic learners accept the idea that multiple positions exist and that each position is equally valid. In other words, multiplistic students subscribe to the "everyone is entitled to their own opinion" mindset. Finally, learners who progress to the relativistic stage retain the multiplistic idea surrounding the existence of multiple positions or viewpoints; however, this is now coupled with the belief that some of these positions are more valid than others under certain circumstances. It is important to note that the final stage of the Perry scheme, commitment in relativism, is concerned mainly with ethical development and is rarely encountered in undergraduate students.

Since the publication of Perry's initial scheme, a great deal of research has been conducted to explore its boundary conditions, focusing specifically on epistemological development in women ${ }^{3}$ and integrated populations at other institutions. ${ }^{4-7}$ Although these studies have led to modifications in Perry's scheme, the basic structural ideas have remained intact with the retention of a stepwise developmental model. More recently, other researchers ${ }^{8-10}$ have argued that epistemological development is not one-dimensional and likely does not occur in a fixed progression of stages. Instead, epistemological development is contextual and composed of multiple factors, often referred to as beliefs, which likely develop independently of each other. For example, Schommer ${ }^{8}$ identified four separate beliefs that contributed to students' epistemological development: students' beliefs about innate ability; students' beliefs about how quickly learning occurs; students' beliefs about the complexity and interconnectivity of knowledge; and students' beliefs about the certainty of knowledge. Yet others ${ }^{11,12}$ contend that understanding epistemological development requires understanding "resources, units of cognitive structure at a finer grain size than stages, beliefs, or theories." 11 In other words, Hammer and Elby posit that even the beliefs-based models championed by researchers such as Schommer-Aikens ${ }^{10}$ are too coarse and do not sufficiently portray the factors that influence epistemological development.

Despite the lingering questions as to how epistemologies develop, there is no question about the essential role that these beliefs play in the learning process. Research with children identified a link between belief in the absolute nature of knowledge and the likelihood of displaying "helpless" behavior when faced with difficult tasks. ${ }^{13}$ Studies performed with adults have also shown a connection between more mature epistemological beliefs and deeper, more conceptual learning, , $^{2,14-17}$ leading to enhanced academic performance. ${ }^{12,18-20}$ Beyond academic performance, however, students who possess more mature epistemological beliefs are better problem solvers and

Published: July 12, 2013 
more metacognitive in their learning. Research conducted in the field of accounting ${ }^{21}$ and mathematics ${ }^{22}$ reveals that students who believed in the uncertainty of knowledge were better equipped to critique data and its quality. Phillips reported ${ }^{21}$ that accounting students who possessed less naive epistemological beliefs were more likely to evaluate what they read and learned for meaning, directly influencing how they approached solving problems. ${ }^{21}$ In comparison, students who felt that knowledge was simple and absolute were more likely to use simple repetition and memorization strategies when learning. ${ }^{23}$ SchommerAikens and Easter ${ }^{24}$ concluded that the use of such strategies was not conducive to the patterns of thought required of effective problem solvers. Further, because personal epistemological beliefs allow us to understand more about effective learning, they may help mediate other beliefs: the essence of metacognition. ${ }^{10,25}$ These strategies are particularly important during the first-year college experience as students work their way through the transition from secondary to tertiary education.,

Given the goals of many introductory science courses to foster critical thinking and problem-solving abilities in students, and the fact that these courses routinely are taken by students during their first year of tertiary instruction, it is clear that developing more mature epistemological beliefs should be of the utmost importance and may be important to their success in the course. It was the purpose of this research, therefore, to explore epistemological development in tertiary chemistry and to document the factors, both curricular and extracurricular, that contribute to this development.

\section{Discipline-Specific Epistemological Beliefs}

Until the introduction of beliefs-based epistemological models, it was assumed that epistemologies were uniform across disciplines. It was assumed, for example, that students with mature epistemological beliefs about learning history also possessed mature beliefs about learning physics or chemistry. More recently, however, researchers have recognized the contextual nature of epistemologies and that learners can possess naive beliefs in some areas while holding mature beliefs in others. These realities, therefore, highlight the need for discipline-based epistemological studies.

Of most relevance to the current research are the epistemological studies that have been conducted in physics. Building upon the work of Hammer and Elby, Redish, Saul, and Steinberg created the Physics Expectations Survey (MPEX) to quantitatively measuring students' epistemological beliefs about learning physics. ${ }^{26}$ During the course of their research, the instrument was administered to approximately 1500 students at six different universities who were enrolled in the first semester of calculus-based physics. The survey was administered at both the beginning and end of the semester in hopes of capturing any changes that occurred as a result of instruction. When students' epistemological beliefs were compared to those of physics faculty, they were statistically less mature. Guided by Perry's research, ${ }^{1}$ Redish and co-workers hypothesized that this gap would close over time; however, that was not the case, and in fact, the gap between teacher and learner only widened further over the course of the semester. ${ }^{26}$ In an effort to reverse this trend, Redish and Hammer ${ }^{28}$ created a "reformed teaching environment" specifically designed to help introductory physics students develop their conceptual understanding of physics concurrent with the development of more mature epistemological beliefs. Assessment of this environment has shown it to be highly successful in both regards, indicating that interventions specifically designed to target epistemological development can be effective. ${ }^{27}$

\section{The Chemistry Expectations Survey}

The findings reported by Redish, Saul, and Steinberg also guided our early investigations in chemistry. Given the surprising findings of Redish's work, the question arose as to whether a similar phenomenon existed in chemistry. How is the domain of student beliefs characterized with regard to learning chemistry? How do students' beliefs for learning chemistry change across the undergraduate chemistry curriculum? How do such beliefs compare to those of chemistry faculty? The desire to answer these questions led to the development of CHEMX, the Chemistry Expectations Survey. ${ }^{28-30}$

CHEMX, which is loosely based upon MPEX, is a 47 -item instrument that contains seven clusters: concepts, effort, laboratory, math-link, outcome, reality-link, and visualization. Table 1 includes a sample statement from each CHEMX cluster, along with descriptions of the favorable and unfavorable view of each dimension. A more detailed description of the instrument and its development is available elsewhere. ${ }^{28}$

During our initial explorations of students' beliefs about learning chemistry, a cross-sectional group of undergraduate chemistry students $(N=597)$ from four institutions completed an online version of CHEMX at least once over a nine-month period. ${ }^{28}$ Considering the original MPEX results, we hypothesized that a statistically significant gap would initially exist between teachers and students: a gap that would widen as the first semester of general chemistry progressed. Although our data did reveal a statistically significant gap between faculty and their students, no significant increases or decreases were observed during the first semester of general chemistry. Indeed, the hypothesized decline in students' beliefs was not observed until the end of second-semester general chemistry when significant decreases were observed in each of the seven CHEMX clusters and overall. After general chemistry, students' beliefs subsequently matured during organic chemistry and upper-level chemistry courses during their second, third, and fourth years. ${ }^{28}$

In order to gain better insight into these trends, we conducted additional analyses using demographic information such as major, sex, and ethnicity as covariants. The results of these analyses showed not only significant differences between males and females but also striking differences in how beliefs of chemistry majors changed in relation to nonchemistry majors. At the beginning of general chemistry 1, the CHEMX data indicated that females had more mature beliefs surrounding learning in the laboratory, the effort required to learn chemistry, and the ultimate outcomes of learning chemistry. Although females consistently maintained their mature outlooks for these three clusters, it was not until the end of the third year that males matured to the point that the differences were no longer statistically detectable. $^{28}$

Additional analyses indicated that the beliefs of students majoring in chemistry steadily improved over the first two years of college chemistry. Simultaneously, nonchemistry majors experienced sharp, prolonged declines. Interestingly, analyses revealed that nonmajors began their study of chemistry with beliefs more closely aligned with those of chemistry faculty than did the chemistry majors. Paradoxically, as the nonmajors continued their study of chemistry during the next two years, their belief became less and less favorable, digressing further from faculty, to a point that in the case of some CHEMX clusters, they selected unfavorable responses $100 \%$ of the time. In contrast, students who intended to major in chemistry began with beliefs about learning the subject that were far removed from faculty and their nonmajor peers. Despite these sizable 
differences, many continued to major in chemistry and moved closer to the beliefs held by faculty during the subsequent four semesters. ${ }^{28}$ These findings offered quantitative insight into the departure of both Tobias' "second tier" and Seymour and Hewitt's "switchers"31,32 and suggested that beliefs about learning may be integrally connected to these decisions.

\section{CURRENT RESEARCH}

Given the essential role that students' epistemological beliefs play in influencing such a wide-ranging collection of attitudes and actions, a better understanding of how these beliefs develop in chemistry is imperative. A one-to-one correspondence between the beliefs measured by the CHEMX instrument and epistemology does not exist nor is implied: in other words, CHEMX was not specifically designed per se to measure epistemology. At an operational level, epistemology is concerned with students' beliefs about the very nature of learning. What does it mean to know something? How does the learner know if she or he knows it? What form will learning take, that is, what activities will the learner be expected to engage in? What skills and or habits of mind will study of the subject require? In this light, we believe that a certain level of overlap exists between the construct of "cognitive expectations" and epistemology, and more importantly, that CHEMX, when used as part of a multimethod inquiry, can provide unique insights into certain aspects of epistemological development. Therefore, it is the purpose of this research to explore the factors that influence the development of epistemological beliefs for learning chemistry; this manuscript will specifically present the results of these efforts from the time that undergraduate students begin their study of general chemistry until they finish organic chemistry, a point after which many nonchemistry majors conclude their study of chemistry.

\section{THE RESEARCH ENVIRONMENT}

This study was conducted at the University of North Carolina Wilmington (UNCW), a public institution in the southeastern United States with an enrollment of approximately 14,000 undergraduate and graduate students. Although the Department of Chemistry and Biochemistry offers multiple sections of each introductory (general chemistry and organic chemistry) course each semester, the courses are coordinated. In other words, all sections of first-semester general chemistry, for example, use the same syllabus and content schedule, grading policies, and course, laboratory, and examination materials despite having multiple instructors. Although students were assessed in both courses using a variety of methods (quizzes, laboratories, online homework, and exams), most of the final grade is derived from the results of three multiple-choice exams and a comprehensive multiple-choice final. Note that approximately one-third of the organic chemistry exams included mechanism and synthesis-type questions instead of multiple choice.

\section{METHODOLOGY}

During the fall of 2010, 15 students from general chemistry 1 were identified. These students were purposefully selected ${ }^{33}$ to ensure diversity in both sex ( 8 females and 7 males) and major ( 8 chemistry majors and 7 nonchemistry majors). Given the typical population that takes general chemistry at UNCW, all participants were first-year students with the exception of one second-year student. During the first two years of the study, we asked students to complete an online version of CHEMX five times: once at the beginning of general chemistry 1 ; 
the second time at the conclusion of general chemistry 1 ; the third at the conclusion of general chemistry 2 ; the fourth at the conclusion of organic chemistry 1 ; and the fifth time at the end of organic chemistry 2 . We also ask them to sit down with us once a semester to reflect upon how and why their epistemological beliefs had or had not changed during that time period.

Each semester, students' CHEMX responses were used to generate graphs showing changes pre- and posttreatment (taking the course). An example graph from one participant is shown in Figure 1. The responses to each CHEMX statement

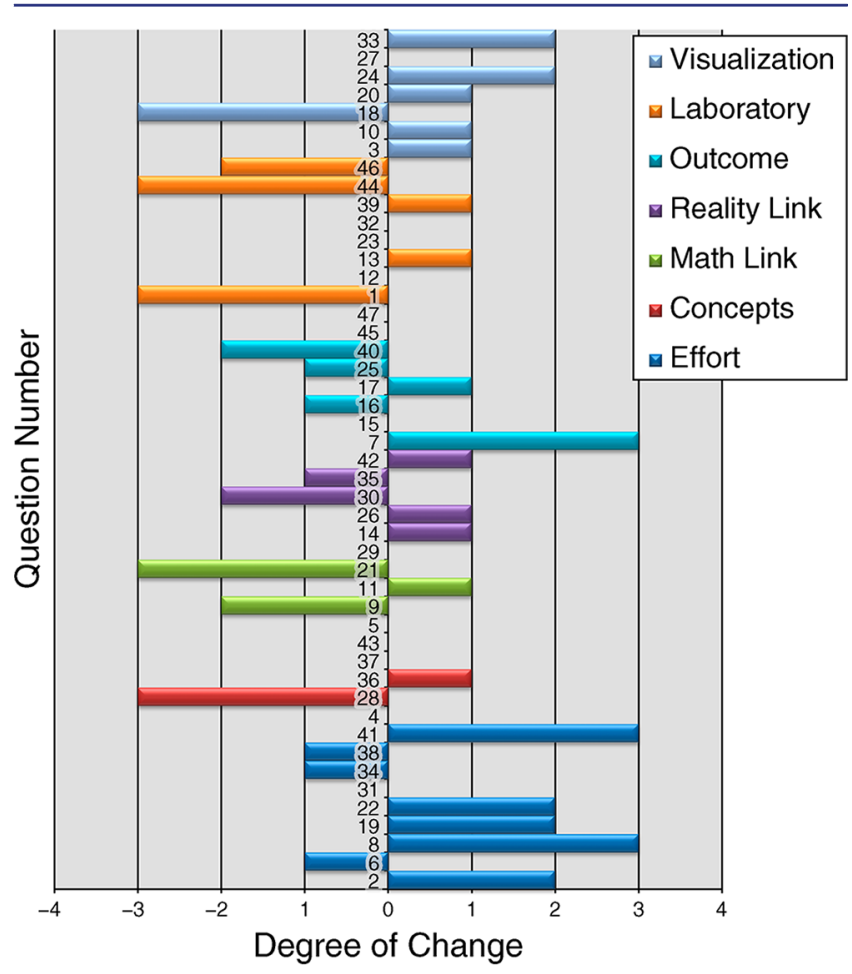

Figure 1. Example graph showing changes pre- and posttreatment (taking general chemistry 1 ) for one participant.

were first organized by cluster, and those collected during one survey administration were compared to responses collected during the previous administration. In the example shown in Figure 1, responses collected at the end of general chemistry 1 were compared to those collected at the beginning, with any changes indicated using a bar. In addition to indicating change, the bars also enabled us to conveniently indicate the magnitude of change and direction (positive, more mature development by bars to the right side, negative, more naive development by bars to the left). These representations allowed us to quickly hone in on specific changes in beliefs between two survey administrations, comparing shifts for each student individually and holistically for all participants.

Note that because of the extremely small numbers involved, and our desire to focus on more individual changes, statistical analyses were not performed on the data: the "quantitative" data was used exclusively to help focus the areas explored during follow-up interviews. Further, it is important to acknowledge the limitations associated with repeated administration of the same instrument over an extended period of time. Such actions can sometimes skew results because students either recognize survey items and quickly answer without deeply thinking about their views or change their own views as a result of engaging in the research activity.
In considering the example presented in Figure 1, this specific student experienced an overall negative development of beliefs associated with the role of the laboratory in learning chemistry. Our interview questions were subsequently tailored in an attempt to capture the sources of such change. Given the fact, however, that CHEMX was not designed to specifically measure epistemological beliefs, the interviews also included several prompts based on statements found in Baxter Magolda's Measure of Epistemological Reflection, ${ }^{34}$ and Schommer's Epistemological Beliefs Questionnaire: ${ }^{10}$ two of the more commonly used instruments to measure general epistemic beliefs.

The interviews, which were semistructured ${ }^{35}$ in their format, were recorded using a digital voice recorder and transcribed verbatim. The interview transcripts were repeatedly analyzed for emergent themes or trends, ${ }^{36}$ and as these themes and trends emerged, subsequent interviews were modified to capture opportunities to better understand the emergent data. Accordingly, the qualitative findings were fundamentally grounded in the data and continually refined as more data were collected. The coding process began with one of us (K.M.M.) carefully reading each interview several times and organizing students' responses based upon broad commonalities. As more responses were gathered from participants, these broad commonalities were subsequently organized into more specific themes and codes and a detailed description for each was generated. We both (K.M.M. and N.P.G.) collaborated to randomly sample student responses and then independently coded them using the developed coding scheme. Any discrepancies were discussed, and the coding descriptors were clarified until the point at which we agreed greater than $70 \%$ of the time. In this way, we were able to provide greater understanding on the trends identified in the CHEMX data and expound upon the important factors that influenced the epistemological development of the students in our study. All phases of this research were approved by UNCW's Institutional Review Board, and informed consent was obtained from all participants before completing all research activities.

\section{RESULTS AND DISCUSSION}

\section{CHEMX Results}

As indicated above, pre- and posttreatment change graphs were generated for each student, each semester. Afterward, the graphs were analyzed for what we considered to be "large" shifts in students' beliefs about learning chemistry; in these instances, we considered a change of two or greater Likert-scale units in either positive or negative directions to be noteworthy. During the first semester of general chemistry, we recorded nearly ten large shifts per student: $70.2 \%$ were negative, that is, students indicated a less mature view of some aspect of learning chemistry at the end of the semester than when they started. Interestingly, the majority of these large shifts (65.0\%) were confined to statements comprising three CHEMX clusters: effort, laboratory, and visualization. In the case of the effort and visualization clusters, the overall trend was not clear, as both positive and negative developments were noted. All shifts observed in laboratory cluster questions were negative.

Given the overwhelmingly negative response to their general chemistry 1 laboratory experience as measured by CHEMX, we felt it prudent to explore these issues with students during our subsequent interviews. Because more than half of the students experienced large, negative shift associated with two 
CHEMX statements, we decided to use these as prompts during the interviews:

Statement 1: "I can do well in the chemistry laboratory (C grade or better) without understanding the chemical principles behind the labs."

Statement 23: "I really don't expect to understand how laboratory instruments work-they are just tools that help me complete the lab."

Further, we also asked students to consider CHEMX statement 37 as a means of initiating our discussions surrounding the changes noted in the effort cluster.

Statement 37: "Understanding chemistry means being able to recall something you've read or been shown."

During general chemistry 2, the pace of negative responses began to slow-in this case, only $50 \%$ of the large shifts were negative. Similar to the general chemistry 1 results, the most dramatic shifts in students' beliefs occurred in the effort and laboratory clusters, again with the laboratory cluster shifts being almost exclusively negative. Additionally, we also observed sizable shifts in the concepts and outcome cluster statements. In looking at these new clusters and how students responded to them, the participants were sharply divided about the appropriate use of equations in chemistry; namely, whether it was sufficient to simply be able to plug numbers into an equation and compute the answer versus the necessity of developing a sound, conceptual understanding of the various components of the mathematical expression, and whether chemistry as a discipline consisted of a series of unrelated facts or an integrated, conceptual whole. To explore these new trends during the interviews, we included these CHEMX statements:

Statement 4: "Problem solving in chemistry means matching problems with facts or equations and then substituting values to get a number."

Statement 16: "Knowledge in chemistry consists of many pieces of information, each of which applies primarily to a specific situation."

Statement 43: "To be able to use an equation in a problem (particularly in a problem I haven't seen before), I need to know more than what each term in the equation represents."

Statement 1 was also retained from the first set of interviews to continue our study of the students' general chemistry laboratory experience.

Consistent with the trends reported in the original CHEMX work, ${ }^{28}$ predominately positive shifts began to appear during students' study of organic chemistry. In the case of organic chemistry $1,54 \%$ of the documented large shifts were positive; $62.5 \%$ of those in organic chemistry 2 were as well. Perhaps the most dramatic differences observed during this time period were those surrounding the laboratory cluster statements. As described previously for general chemistry 1 and 2, the vast majority (89.2\%) of large shifts in laboratory cluster statements were negative. By the end of organic chemistry 2 , this trend had flip-flopped, with nearly $60 \%$ positive shifts.

Beyond the improvements in the laboratory cluster, we also continued to observe large shifts within the concepts and outcome clusters, again centered around the same general themes outlined above. As such, the organic chemistry interviews also included the following CHEMX statements:

Statement 9: "In this course, I do not expect to understand equations in an intuitive sense; they just have to be taken as givens." Statement 15: "A good understanding of chemistry is necessary for me to achieve my career goals. A good grade in this course is not enough."

Statement 37: "Understanding chemistry means being able to recall something you've read or been shown."
In addition, the four statements used during the general chemistry 2 interviews were also retained.

Interview Results

As detailed previously, interview transcripts were repeatedly analyzed in an effort to provide context to the trends in the CHEMX data to begin to identify and to understand the curricular and extracurricular factors that influence epistemological development among chemistry students. These factors are outlined below. It is important to recognize the tentative nature of the interview results and the fact that the students' perceptions of the factors that influenced their beliefs, decisions, and actions may have been, and quite likely were, swayed by other implicit factors such as their personal interests in chemistry and career aspirations, their overall maturity, and the teaching skills of their professors and teaching assistants.

Influence of Grading Policies and Course Structure. The grading policies and structure of the introductory courses our participants were enrolled in during their first two years had a tremendous impact on their epistemological development and, ultimately, how those beliefs manifested into how the students approached their learning of chemistry. Not surprising, many of the novice students involved in our inquiry were generally unaware of their own role in the learning process and frequently could not articulate how or if they knew something. When students were able to express their own beliefs about the learning of chemistry, they often placed themselves in a passive, submissive role. For example, Pearl told us toward the end of first-semester general chemistry that

$[L]$ earning is someone laying out information or you read information or an intake of information...my responsibility is to take the information that I'm given and remember it.

Similarly, Andy noted that he "will think back to text from the book...just fall back on what you read or what you were shown." Interestingly, this last quote was an almost word-for-word restatement of CHEMX statement 37 and the unfavorable view associated with the effort cluster.

While it was certainly true that the majority of students spoke about passive learning approaches, there were a few who did possess more nuanced understandings of the complexities of learning chemistry. Even at this early juncture, they held a belief that learning chemistry was not simply about memorization; instead, a "learn and apply" approach was required. Mike, for example, felt that chemistry was

$[K]$ ind of like math. People can show you how to do things all day long, but if you do not practice it yourself, then when you actually have to do it, it makes it five times harder. Unfortunately, within the course structure and assessment practices found in general chemistry, which provided students exclusively with multiple-choice exams and a quite generous exam replacement policy (students could replace all exam scores earned during the semester with the results of the final), they often found it unnecessary to adopt a deep, active approach to learning chemistry. Although such replacement policies were originally adopted in an effort to provide students additional time to "digest" and master course material, they may also have had a deleterious impact on the level of effort students felt was necessary in order to learn chemistry. Indeed, several students reported little concern for their low exam scores during the semester because as long as they "memorized" everything by the time of the final, they would still be able to earn a good grade in the course. 
During organic chemistry 1 , we observed a definite shift in how the students approached learning chemistry, with the vast majority (80\%) moving from the less meaningful, memorizational approaches described above to the more meaningful, mature approaches used by those like Mike. As Dori explained:

$[W]$ ith organic I have to sit and work out problems and actually do homework, practice reaction problems...In general chemistry it was just more like memorization.

Colette described her day-to-day study habits thus:

$[N]$ ormally day-to-day...I'll go through, after lecture I'll go through and do those [homework problems] and when it comes time for the exam I'll read through the chapters and do problems again.

Students reported that these more mature approaches were required because of the changes in assessment practicesstudents were now required to answer more in-depth essay, mechanism, and synthesis questions on exams - and because of an overall increase in the instructors' expectations for the students.

After observing such positive developments during the first semester of organic chemistry, and considering the overwhelmingly positive developments documented in the CHEMX results, we expected a continued improvement during organic chemistry 2. Interestingly, however, many of the students instead reported a regression in their learning approach. For example, Jessie reported that during her first semester of organic chemistry, her study habits were quite active and led to what she felt was a solid understanding of the material. She practiced a pattern in which she

$[U]$ sed the book before class and read the section that we are supposed to go over...go to class...do the practice problems within a day or two after class...review my notes.

The course, in her opinion, required nothing less. During the second semester, however, she drifted away from these approaches and instead slipped back into a pattern characterized mainly by memorization. Because of this, she admitted that she did not feel she learned as much:

I'm not really learning a whole lot... [we get] practice tests and you just have to memorize the test and that is the test.

So, it does not really require you to learn why.

When the students were asked to reflect upon this regression at the end of the semester, they attributed it to a perceived lack of support when it came to mechanism instruction during the second-semester course. As Dori explained:

I think that the reason I reverted back to memorization for organic 2 was because the mechanisms were not fully taught to us, so practice was not enough without the memorization.

In organic 1 , if you had no clue what the reactants would form, you could at least arrow-push to figure it out. Because the mechanisms of [organic] 2 were too over our heads to be taught, the easiest way to learn was memorization since a lot of mechanism arrows were left out.

It may be that because such an emphasis was placed on arrow-pushing and mechanisms during the first semester, the faculty believed that students could now use these skills on their own without a great deal of reinforcement. It could be, as Dori speculated, that the mechanisms encountered were beyond the abilities of the typical students enrolled in the course. Whatever the reason, faced with the lack of an effective organizational scheme to guide their learning, our participants fell back on methods, such as rote memorization, that had worked well for them in the past and abandoned some of the more meaningful approaches adopted during organic chemistry 1 .
Influence of the Chemistry Laboratory. One of the more important contributors to epistemological development during the first- and second-year experiences of the students involved in this study was the time they spent in the chemistry laboratory. While speaking with us during general chemistry 1 , many of the students felt that the laboratory experience could be quite powerful. Violet, for example, thought, "What you're doing in class is theory and then you look in lab and you see it actually happening. It kind of clicks, I guess." Mike felt that "[Lab] brings the lecture into reality", and Marlin echoed those same sentiments when he described the lab experience as "concepts in action". In short, the majority of our participants believed that the laboratory experience had the unique ability to connect the theory that was being learned in lecture with the physical world around them.

Clearly, these students had high expectations for their general chemistry laboratories and the impact it could have on their understanding of chemistry; unfortunately, the reality they encountered did not live up to those expectations. Because of the expository nature of the lab experience, students found little incentive for adopting meaningful approaches for learning the material and for trying to actively connect what was learned in lecture with that in lab. In talking about her observations of her classmates, Dori explained:

I know people that struggled through the [lecture] and did not understand it, but could, you know, function in the lab and do what the manual told them to do. They can follow directions. They do not necessarily know why they're doing it or what they're doing exactly....

Sally admitted to doing just that:

I hate that I do it, but I do it.... I usually do not read the laboratories before the actual lab. I'm in a group of peopleyou just all work together, get it done really fast, and go through the lab like it says to do [in the lab manual] and we do well.

Because of these realities, Edna found "the lab to be very tedious...I feel like I'm just wasting my time sometimes”, and Marlin conceded to being disappointed because he thought the laboratories "would be more in-depth" than what he encountered. While students recognized this was not what they were "supposed to do", there was general agreement that it occurred frequently throughout the students' first year. These sentiments provided a great deal of insight into the highly negative shifts observed in the CHEMX laboratory cluster during this time period. Not only were many students disappointed, the lab structure encouraged some students to pursue less mature epistemological stances. Students' cognitive resources are limited, and they must make tough, calculated choices as to how to spend them. If connections between the laboratory experience and lecture were not clear and if students could find ways of quickly completing the laboratories while still earning good grades, why would they not do so?

As our participants continued into organic chemistry, they found their second-year laboratory experiences to be much more enriching. The students thought that the lecture and laboratory courses were in greater synchronization, and for students such as Dori, this was an advantage:

[Organic lab] applies to lecture a lot more...the reaction [performed in lab] is demonstrating what you were taught on paper in your lecture and it shows what's happening. I think physically being able to make it makes [the material learned in lecture] stick a little better.

Further, students felt that the organic lab was structured in such a way as to prompt critical thinking about their actions 
and penalized those students who elected not to do so or attempted to circumvent the process. As Collette explained, this was different from general chemistry: " $[\mathrm{W}]$ ith organic lab, you definitely have to understand why you are doing what you are doing; whereas, general chemistry you can kind of just go through it." Many of the students attributed these differences to the experiments being more demanding and to being required to produce formal reports at the end of each lab that prompted students to think critically about what they had just done.

The experiences of the students involved in this research clearly document how important the laboratory experience can be to students' epistemological development. It is interesting to note that these students were critical of an experience that was designed to be as streamlined and straightforward as possible and instead appreciated and preferred the experience that was more difficult and more time-consuming. These results would seem to contradict the belief held by some chemistry faculty that their students are simply looking to expend as little time and effort in lab as possible, and instead suggest that some students behaved in that manner only grudgingly and as a result of the laboratory structure and assessment practices they encountered.

Influence of Other Students. Other students, and the sense of community that these participants derived from interacting with their peers, were an important contributor to epistemological development. A typical general chemistry lecture at UNCW contains approximately 120 students who are further spilt into five laboratory sections of 24 students each. By breaking the larger lecture sections up into smaller, more intimate ones, we hoped this would foster a sense of community among the students. Despite these deliberate attempts at facilitating community development early in general chemistry, it was not until after the first semester of organic chemistry that students started to talk about studying in groups and learning from other students. For example, Violet talked about her study sessions during organic chemistry 1 with a friend who was

$[R]$ eally studious and so we would study together. So, that actually helped quite a bit.... Just his being around makes me realize I need to study, it is almost competitive.

Colette also talked about how she and a friend studied together: "[W]e will get together and do reactions on the white board in the study room.... When we do things on the white board, like, we'll quiz each other." Overall, the students reported adopting a more active learning approach when working with other students and found it a positive experience. As was the case with Violet, they also reported that working with these students had direct impact on how they approached their own learning.

Why, then, did they not start this process before organic chemistry? In some cases, the students did not feel the need to do so: general chemistry 1 and 2 were "straightforward" and not difficult for some of them. In other words, students viewed the community only as a source of remediation. In other cases, however, participants reported that our efforts at fostering community were tenuous. As Jessie explained:

$[T]$ he nature of the people who take the course [general chemistry]...[is] you have a handful of people who are freshman and sophomores in college so they do not know a lot of people.... did not really know anybody in any of my

classes...there's such a large lecture that it does not really force you to talk to anyone.

Other research has pointed to the essential role that community, or a perceived lack thereof, can have on students' learning and their decisions to pursue careers in STEM.
Seymour and Hewitt, ${ }^{32}$ for example, found that nearly $17 \%$ of their switchers-students who started their college career as STEM majors but subsequently switched to a non-STEM field-cited issues surrounding community as a contributing factor in their choice. These issues, which seem to impact women and minority students more than men, ${ }^{32}$ also were cited by the second-tier students who participated in Sheila Tobias's work. These students consistently found the individualistic and competitive nature of many science courses to be unappealing. ${ }^{31}$ In all likelihood, these issues of community, among others, may have dissuaded some talented students from pursuing careers in the sciences. ${ }^{31}$

\section{- CONCLUSIONS}

Students' epistemological beliefs - the beliefs they hold about the very nature of learning-are essential to the attitudes, beliefs, and expectations that students bring to their study of chemistry. The current inquiry was a beginning attempt at better understanding how those beliefs developed during students' study of chemistry during general and organic chemistry.

Our results, while preliminary, strengthen the idea that epistemological development is contextual in nature and that stepwise developmental models such as those posited by Perry are too coarse to adequately describe the experiences of the students involved in this research. Epistemological development was not one-dimensional, and while commonalities did exist among some of our participants, development most certainly was not uniform for all. Instead, the factors that influenced students' epistemological development during their first two years of introductory chemistry may be better described using the beliefs-based or resources-based models advanced by Schommer-Aikens ${ }^{8}$ and Hammer and Elby, ${ }^{11,12}$ respectively, that recognize the importance of more fine-grained epistemological influences on the learner.

The data gathered from the sequential CHEMX administrations provided a great deal of insight into possible avenues of exploration during the follow-up interviews. Of particular note were the shifts surrounding the laboratory, effort, concepts, and outcome clusters. Subsequent interviews identified three broad epistemological influences: (i) course structure and grading policies; (ii) the laboratory experience; and (iii) other students. While other students often had a positive impact on students' epistemological development, the course structure, grading policies, and laboratory experiences-at least as they pertain to the first-year experience-were often negative influences. It is important to note that current policies and assessment practices were not intended as a detriment, but were instead put in place because we believed such actions would be supportive of novice chemistry students and would streamline their experience. It is clear that we succeeded in providing students that streamlined and straightforward environment, but at the same time, we may have inadvertently hindered their epistemological development; changes are underway to mitigate some of these issues.

We are also seeking additional models of fostering the sense of community missing from students' experiences during their first year. For example, we are currently conducting a pilot study that has coupled a first-year seminar course with a section of general chemistry. In this environment, students not only share the same general chemistry lecture and laboratory sections but also attend the same first-year seminar course. In light of the results of this inquiry, we encourage others, most especially those at universities that also have larger, coordinated general chemistry and organic chemistry programs, to critically evaluate current policies and assessment practices from the perspective of epistemological development. 


\section{AUTHOR INFORMATION}

\section{Corresponding Author}

*E-mail: groven@uncw.edu.

\section{Notes}

The authors declare no competing financial interest.

\section{REFERENCES}

(1) Brownlee, J.; Walker, S.; Lennox, S.; Exley, B.; Pearse, S. Higher Educ. 2009, 58, 599-618.

(2) Perry, W. G. Forms of Intellectual and Ethical Development in the College Years; Holt, Rinehart and Winston: New York, 1970.

(3) Belenky, M. F.; Clinchy, B. M.; Goldberger, N. R.; Tarule, J. M. Women's Ways of Knowing: The Development of Self, Voice, and Mind; Basic Books: New York, 1986.

(4) Ryan, M. P. J. Educ. Psychol. 1984, 76, 248-258.

(5) Glenberg, A. M.; Epstein, W. Mem. Cognit. 1987, 15, 84-93.

(6) Baxter Magolda, M. B. Rev. Higher Educ. 1994, 18, 25-44.

(7) King, P. M.; Kitchener, K. S. Developing Reflective Judgment; Jossey-Bass: San Francisco, 1994.

(8) Schommer, M. J. Educ. Psychol. 1990, 82, 498-504.

(9) Hofer, B. K.; Pintrich, P. R. Rev. Educ. Res. 1997, 67, 88-140.

(10) Schommer-Aikens, M. Educ. Psychol. 2004, 39, 19-29.

(11) Hammer, D.; Elby, A. On the Form of Personal Epistemology. In Personal Epistemology: The Psychology of Beliefs about Knowledge and Knowing, Hofer, B. K., Pintrich, P. R., Eds.; Lawrence Erlbaum: Mahwah, NJ, 2002, 169-190.

(12) Hammer, D.; Elby, A. J. Learn. Sci. 2003, 12, 53-90.

(13) Dweck, C. S.; Leggett, E. L. Psychological Rev. 1988, 95, 256273.

(14) Schommer, M.; Crouse, A.; Rhodes, N. J. Educ. Psychol. 1992, $84,435-443$.

(15) Linn, M. C.; Songer, N. B. J. Dev. Psychol. 1993, 39, 47-73.

(16) Brownlee, J. J. Teach. Educ. Dev. 2001, 4, 167-190.

(17) May, D. B.; Etkina, E. Am. J. Phys. 2002, 70, 1249-1258.

(18) Carey, S.; Smith, C. Educ. Psychol. 1993, 28, 235-252.

(19) Linn, M. C.; His, S. Computers, Teachers, Peers; Lawrence Erlbaum: Mahwah, NJ, 2000.

(20) Smith, C. L.; Maclin, D.; Houghton, C.; Hennessey, M. G. Cognit. Instruct. 2000, 18, 349-422.

(21) Phillips, F. Issues Account. Educ. 2001, 16, 21-39.

(22) Gill, M.; Ashton, P.; Algina, J. Contemp. Educ. Psychol. 2004, 29, 164-185.

(23) Marton, F.; Dall'Alba, G.; Beatty, E. Int. J. Educ. Res. 1993, 19, 277-300.

(24) Schommer-Aikins, M.; Easter, M. Educ. Psychol. 2006, 26, 411423.

(25) Schommer-Aikins, M. An Evolving Theoretical Framework for an Epistemological Belief System. In Personal Epistemology: The Psychology of Beliefs about Knowledge and Knowing; Hofer, B. K. Pintrich, P. R., Eds.; Lawrence Erlbaum: Mahwah, NJ, 2002; pp 103118.

(26) Redish, E. F.; Saul, J. M.; Steinberg, R. N. Am. J. Phys. 1998, 66, 212-224.

(27) Redish, E. F.; Hammer, D. Am. J. Phys. 2009, 77, 629-642.

(28) Grove, N. P.; Bretz, S. L. J. Chem. Educ. 2007, 84, 1524-1529.

(29) Grove, N. P.; Bretz, S. L. Measuring What Students Know about How To Learn Chemistry. In Proceedings of the National Science Foundation Conference, Assessment of Student Achievement; National Science Foundation and Drury University: 2008; pp 159-165.

(30) Mathew, J. M.; Grove, N. P.; Bretz, S. L. Chem. Educ. 2008, 13, 190-194.

(31) Tobias, S. They're Not Dumb, They're Different: Stalking the Second Tier; Research Corporation: Tucson, AZ, 1990.

(32) Seymour, E.; Hewitt, N. M. Talking about Leaving: Why Undergraduates Leave the Sciences; Westview Press: Boulder, CO, 1997.

(33) Patton, M. Q. Qualitative Research and Evaluation Methods; Sage Publications: Thousand Oaks, CA, 2002.
(34) Baxter Magolda, M. B. J. Coll. Stud. Dev. 2001, 42, 520-534.

(35) Bretz, S. L. Qualitative Research Designs in Chemistry Education Research. In Nuts and Bolts of Chemical Education; Bunce, D. M., Cole, R. S., Eds.; American Chemical Society: Washington, DC, 2008; pp 79-99.

(36) Corbin, J.; Strauss, A. Basics of Qualitative Research: Techniques and Procedures for Developing Grounded Theory, 3rd ed.; Sage Publications: Thousand Oaks: CA, 2008. 